\title{
OS TÚMULOS CIRCULARES DE MESARA: CONSIDERAÇÕES SOBRE OS ASPECTOS SOCIAIS
}

\author{
Alvaro Hashizume Allegrette \\ Faculdade de Filosofia, Letras e Ciências Humanas \\ Universidade de São Paulo
}

Resumo: Os túmulos circulares minóicos da planície de Mesara foram analisados aqui visando a identificação de caracteres sociais das populaçōes do Minóico Antigo I-II. Tal investigação mostrou que neste periodo houve a transição de núcleos agro-pastoris autónomos e relativamente isolados para comunidades de economia diversificada subordinadas a uma liderança única regional. Utilizando as evidências presentes nos padrōes de distribuição $\theta$ construção dos túmulos, bem como na composição do mobiliário funerário; observa-se a alteração de elementos e a incorporação de novas produções resultantes dessa nova ordem social:

Palavans-chave: Creta, Civilização Minóica, Túmulos Circulares, Mesara, Idade do Bronze, Práticas Funerárias.

No estudo da sociedade minóica do periodo pré-palacial uma grande parte das informações é proveniente da análise das estruturas funerárias de Mesara, região na parte sul de Creta, que constituem um agrupamento com caracteres definidos, tanto em termos de distribuição espacial quanto temporal (Fig. 1).

Os túmulos circulares da região de Mesara são assinalados em quatro concentrações geográficas distintas, nas encostas litoråneas da vertente sul dos montes Asterousia, nos contrafortes da encosta norte dos montes Asterousia, nas encostas meridionais do monte Ida e na planicie de Mesara propriamente dita. Observaremos que os túmulos freqũentemente estão distribuídos em conjuntos de duas ou três estruturas, sendo raros os exemplares isolados. Exemplares unitários deste tipo de túmulo também podem ser encontrados nas porções norte e leste da ilha de Creta, mas correspondem a menos de um quinto do número total (Branigan, 1970).

Os túmulos mantinham uma relação de proximidade com os núcleos habitacionais. Não há sinal de qualquer preferência por uma posição relativa a estes núcleos. Embora não tenhamos indicios seguros para todos os sítios funerários, tomamos como provável que os túmulos se situassem nos limites das comunidades, em alguns casos havendo uma continuidade entre os vestígios habitacionais e funerários. Observamos que as estruturas habitacionais são de formato quadrangular, contrastando visivelmente com os túmulos circulares, o que poderia constituir um dos sinais de determinação de fronteiras entre os vivos e os mortos.

Os túmulos são construídos em pedra calcárea, com ao menos duas camadas de blocos, uma externa e outra interna, muitas vezes separadas por uma 
camada intermediária de terra e seixos. 0 diâmetro interno varia entre $2,4 \mathrm{~m}$ e 13,1 $\mathrm{m}$, mas apresenta uma média de $6,0 \mathrm{~m}$. Há uma tendência para a instalação da entrada a leste, a qual mede cerca de 1,2 m de altura e 1,0 m de largura, usualmente estando fechada por placas de calcáreo.

Dos quarenta e dois túmulos estudados, notaremos que vinte e três apresentam uma antecâmara de dimensōes não superiores a 2,54 x 1,0 m (caso de Platanos A) e ainda teremos em outros casos a presença de câmaras anexas retangulares construidas junto à entrada dos túmulos, de configuração similar aos túmulos quadrangulares assinalados nas porções central e oriental de Creta. Cronologicamente esse anexos são contemporåneos dos túmulos quadrangulares, uma explicação aceitável seria a de que teria havido uma interpenetração das populações de Mesara e de Creta Central e Oriental a partir do Minóico Antigo II, enquanto que os túmulos circulares foram assinalados desde o Subneolítico (Petit, 1983). Percebemos também que em ao menos três casos os anexos são posteriores ao túmulo circular em si (casos de Lebena II, Platanos A e Porti).

De acordo com os indicios encontrados nos túmulos, a forma corrente de enterramento era a inumação, sendo que vestígios de ossos carbonizados interpretados anteriormente como sinais de cremação foram reinterpretados como resultado de queima acidental durante 0 processo de fumigação dos túmulos, do que há evidências em outros nos quais os ossos não foram carbonizados. No entanto a caracterização da forma de deposição ainda é conjectural, pois a análise do conteúdo dos túmulos tem sido prejudicada por dois fatores: primeiro, os saques ao longo dos séculos, que perturbaram a disposição dos vestígios e eliminaram outros; em segundo, pela manipulação deliberada dos restos humanos no interior dos túmulos, com o seu deslocamento para as paredes e a desarticulação dos esqueletos, freqüentemente com a remoção dos crânios e sua deposição em separado (caso de Hágia Tríada A, Platanos B e Koumasa B). A manipulação dos restos humanos que foi assinalada nos túmulos pode ser relacionada à realização de enterramentos secundários, o que nos parece uma hipótese viável se considerarmos o número de indivíduos depositados nos túmulos. As estimativas de Xanthoudides apontam centenas de indivíduos nos túmulos de Koumasa B, Marathokephalon, Porti, Hágia Triada e Vorou A e B; para Kamilari e Lebena I, o total chegaria a mais de quinhentos individuos em cada um desses túmulos (cit. em Branigan, 1970, p. 129). Desta maneira a remoção dos restos de enterramentos anteriores se configuraria como uma necessidade vinculada possivelmente à conservação dos crânios acima citada, por terem estes uma importåncia particular para os minóicos, visto serem escolhidos para guarda em separado (Branigan, 1987).

Consideremos agora o mobiliário funerário. Ele é composto por dois grupos distintos de artefatos: 0 de objetos ligados aos ritos de enterramento e aquele de objetos que poderiam ser tanto propriedades pessoais do morto quanto indicadores de sua condição social. 0 grupo de artefatos de caráter ritual engloba vasos cerâmicos e vasos de pedra, com a presença de jarros, taças e tigelas como formas mais freqüentes da ceråmica, e de kernoi, vasos tubulares e nidiformes para aqueles feitos em pedra. Estes últimos ainda provêm quase que exclusivamente de contextos funerários, 0 que nos permite relacioná-los com boa margem de segurança às atividades assim qualificadas.

A associação do material cerâmico aos ritos funerários pôde ser confirmada com a descoberta de dezenas e até centenas de exemplares intactos ou 
fragmentados no interior dos túmulos e nas antecåmaras, o que sugere uma importância para tais vasos que não se vincularia à sua posse pelo morto, já que os objetos pessoais seriam colocados junto aos restos humanos, enquanto que os vasos cerâmicos estavam espalhados no interior dos túmulos ou amontoados nos anexos.

Os objetos definidos como pertences pessoais ou indicadores de condição social do morto são em quantidade bem menor e em maior variedade, incluindo amuletos, selos, adagas, jóias, figurinhas, utensllios e núcleos de obsidiana, arpões, serras, cinzéis, machados, raspadeiras, pinças e escaravelhos. Embora sejam poucos os túmulos sem sinais de perturbação, a presença em grande número de adagas, de raspadeiras e de pinças permitiu considerar que o sexo do morto fosse geralmente indicado pela presença de uma adaga, no caso dos homens e por uma raspadeira ou um par de pinças no caso das mulheres. Keith Branigan sugere que a existência de uma figurinha também indicasse o sexo feminino, pois seria utilizada por mulheres no parto; entretanto não temos indícios que comprovem sua hipótese com respeito à civilização minóica (Branigan, 1970).

Certos artefatos presentes nos túmulos parecem estar relacionados às atividades desenvolvidas pelo morto durante sua vida, como no caso dos arpões, que seriam os utensilios que caracterizariam 0 trabalho de um pescador; dos núcleos e utensílios de obsidiana para os artffices deste material; das serras e furadores para os carpinteiros. Da mesma maneira que serviriam como indicadores de suas funçōes em vida, sugerem a existência de categorias profissionais especializadas, o que é particularmente evidente quando consideramos os selos, que aparecem em número e variedade suficientes para que se pense em oficinas locais com produçōes especializadas distintas, constatação assegurada pela análise dos motivos, técnicas e formas dos mesmos; e os utensflios de bronze (como pinças, raspadeiras, serras, furadeiras e adagas), cuja produção exige um certo grau de conhecimento das técnicas metalúrgicas.

Os selos formam uma categoria de artefatos pessoais cujo significado estaria ligado a duas funções, a de sinais individuais de propriedade e a de indicadores de posição social do individuo. A frequência de determinados signos sugere que fossem sinais de clãs ou de assentamentos especificos; porém a sua ocorrência não se restringe a um determinado grupo de túmulos, embora existam concentraçōes em alguns deles, como em Hágia Tríada A; outra interpretação propōe que fossem signos indicativos de cargos administrativo-politicos, visto que a regularidade de sua ocorrência em túmulos construidos a partir do Minóico Antigo II seria compativel com a fase de transição de comunidades auto-suficientes para um sistema de unidades administrativas sob governo único. Veremos mais sobre esse assunto posteriormente.

Do conjunto desses artefatos, temos ainda a indicação de contatos comerciais com outras culturas e regiōes do Mediterråneo: muitos dos selos encontrados têm como matéria-prima o marfim e matérias minerais, que poderiam provir somente de outros pontos do Mediterrâneo; a obsidiana provinha essencialmente da ilha de Melos, no Egeu, o marfim utilizado nos selos teve sua provável origem determinada como a Siria e o Egito, da mesma maneira que os escaravelhos se originariam deste áltimo, indicando um grau de desenvolvimento econômico que já teria ultrapassado o nivel da agricultura de subsistência e dos contatos locais, incorporando a navegação em alto-mar como atividade regular. Da 
mesma forma, a presença de artefatos de bronze em profusão nos sugere que a metalurgia se encontra desenvolvida o suficiente para permitir a elaboração local de instrumentos, utilizando uma tecnologia cujas fontes talvez estivessem em Chipre, conforme os resultados da análise da composição dos metais empregados em tais utensílios e pela observação do contexto de achado de objetos similares em Chipre, associados a material minóico.

A partir destas observaçōes, duas consideraçōes poderiam ser feitas a partir da análise do conteúdo desses túmulos, todas relacionadas ao problema do conhecimento de aspectos da sociedade minóica pré-palacial:

1. Parte do mobiliário colocado junto ao morto pertencia a este e poderia corresponder às atividades desempenhadas pelo indivíduo na comunidade, sendo indício de atividade especializada;

2. Certos tipos de artefatos indicam um novo grau de desenvolvimento tecnológico e econômico, como é o caso dos utensílios de bronze e dos selos, que só poderiam ser produzidos com um incremento no nível de organização social e econômica que possibilitassem a obtenção de materiais e técnicas inexistentes em Creta no MA I, pois significaria a existência de um comércio ultramarino regular e portanto, além do nivel das trocas locais ou regionais, o que caracteriza uma sociedade e uma cultura que ultrapassou o nivel das comunidades agricolas autosuficientes.

No entanto, os sinais de tais transformações se encontram distribuidos de forma heterogênea em Mesara, pois ao mesmo tempo em que são abundantes na planície e nos contrafortes norte da cadeia dos montés Asterousia, são escassos na porção sul desta cadeia e nas encostas do monte Ida. Uma explicação possivel seria a de que teria existido um descompasso no desenvolvimento sócio-econômico destas duas áreas durante o Minóico Antigo II, período em que tais transformações tiveram lugar.

Partindo dessa perspectiva, exporemos alguns indícios que podem levarnos à consideração de que na região de Mesara ocorreram mudanças significativas entre o MA I e o MAII. Vejamos quais são estes indicios:

Os objetos de bronze encontrados nos túmulos da planície de Mesara e na porção norte da cadeia dos montes Asteroúsia são mais numerosos do que aqueles assinalados nos túmulos da porção sul daquela cadeia e no sopé do monte Ida, o mesmo se verificando com os vasos de pedra e com os selos. No caso dos utensillios de bronze observou-se uma padronização de formas e de proporções no material da planicie, embora sejam percebidas variações técnicas que indiquem a coexistência de produções de artesãos distintos, talvez evidenciando a presença de uma oficina em cada assentamento desta área.

0 mesmo poderia ser dito dos vasos de pedra, pois na mesma medida em que se percebe uma padronização das formas, proporçōes e técnica das produções da planície, notamos 0 emprego de materiais como o diorito e a serpentina, que não são encontrados em Creta, além de variação no volume e na qualidade dos achados nos túmulos da planície de Mesara e da parte sul dos Asterousia que não se explicaria apenas pela pilhagem. Julgamos licito supor que 
seria a presença de artesãos especializados nos assentamentos 0 fator discriminante, 0 que é reforçado pelo achado em um túmulo de dois vasos de pedra inacabados, identificadores do sepultamento de um artesão destes objetos, dos quais citamos casos similares.

No caso dos selos, temos uma variação tanto no volume quanto nos materiais e nas categorias encontradas, com uma quantidade cinco vezes superior na planície, com o uso extenso do marfim e o emprego de signos padronizados correspondentes a produções de oficinas diversas. Branigan e Krzyskowska observam que embora a matéria-prima seja importada, a manufatura é local (Branigan, 1984; Krzyskowska, 1983).

Um último ponto que realça tal distinção entre a planície e os assentamentos meridionais refere-se aos artefatos importados, que são encontrados apenas na planície (constituindo-se de figuras de Philakopi e de Spedos, de escaravelhos e selos escarabóides do Egito, de adagas de prata da Síria, contas de faiança e selos cilindricos da Mesopotâmia).

Uma interpretação dessas diferenças seria possivel caso considerássemos que, a presença de itens de prestígio e aparato, artesãos especializados e a importação de objetos pelo comércio ultramarino, todos assinalados regularmente em uma das áreas estudadas e de forma eventual em outra, correspondessem a dois momentos distintos de desenvolvimento da sociedade minóica durante o MAII.

Ao longo do MA I houve o desenyolvimento de uma série de comunidades autosuficientes, composta por grupos ligados por relaçōes de parentesco, com uma economia baseada na agricultura sedentária, na criação de animais e em alguns casos na pesca, com um artesanato concentrado na transformação de matérias vegetais e animais, mantendo contatos irregulares com outras partes da ilha e com regiōes próximas de Creta. Essas comunidades dispunham de estruturas tumulares circulares de grande porte nas quais ocorria o sepultamento dos membros da sociedade com artefatos de caráter ritual e objetos de caráter pessoal, sem elementos distintivos de categoria socio-econômica. A presença de duas a três estruturas por comunidade sugere-nos que cada túmulo servia a clãs distintos dentro de cada comunidade.

A partir do MA II modificações foram introduzidas, como 0 indicam os itens acima expostos, delineando agrupamentos integrados sob uma administração comum e inseridos em uma rede de relaçōes comerciais locais e ultramarinas. Ocorre uma diferenciação social e econômiça, com a utilização de túmulos para 0 sepultamento de indivíduos pertencentes a categorias especificas, definidas pela posse de determinados artefatos distintivos de prestígio ou aparato e de identificadores de sua função ou categoria social e econômica: conforme a hipótese de Ann Blasingham, estes selos seriam signos correspondentes a cargos da administração local dessas vilas, inseridos no conjunto mais amplo da região de Mesara (Blasingham, 1983, p. 16). Dessa maneira, estabelece-se uma clivagem social inexistente nesta cultura até o MA II, com a definiçăo de uma nova ordem, na qual as comunidades são elementos dentro de um sistema mais amplo que se configurararia a partir do MA III como a sociedade proto-palacial. Esta ordem seria inicialmente instalada nas áreas sob influência imediata do novo núcleo políticoadministrativo da região em Festos, onde se ergueria um dos primeiros palácios minóicos. Assim sendo, as comunidades na porção sul de Asterousia seriam 
absorvidas apenas ao longo do MA III, ao contrário daquelas instaladas na planície e na porção norte de Asterousia.

Abstracr: The circular tombs of Mesara plain were analysed here to attempt the identification of social features of minoan communities at Early Minoan I-II. This research had revealed that in this period a transition between the relatively independents nuclei of agricultural and pastoral economy, and the communities with a diversified economy and under centralized regional leader has took place. By using the evidences presents on the distribution and construction patterns of tombs, and the composition of funerary mobiliary, we will see the changes of elements and the incorporation of new productions resulting from this new social order.

Bibliografia

BELLI, P. Nuovi documenti per lo studio delle tombe circolari cretesi. Studi Micenei ed Egeo-Anatolici, Roma, 25:91-142, 1984.

BLASINGHAM, A. C. The seals from the tombs of Mesara: inferences as to kinship and social organization. In KRZYSZKKOWSKA, O. H. e NIXON, L. (ed.) Minoan Society. Proceedings of the Cambridge Colloquium 1981. Bristol: Bristol University Press, 1983, p. 11-22.

BRANIGAN, K. The Tombs of Mesara. London: Duckworth \& Sons, 1970, p. 182.

. Early Minoan society: the evidence of the Mesara tholoi reviewed. In Aux Origines de l'Hellenisme: Hommages a Henri van Effenterre. Paris: Sorbonne, 1984, p. 29-37.

. Ritual interference with human bones in the Mesara tholoi. In LAFFINEUR, R. (ed.) Thanatos. Les Coutumes Funéraires en Égée à l'Âge du Bronze. Liège: Université de l'État à Liège, 1987., p. 43-51 (s. AEGAEUM 1).

KRZYSKOWSKA, O. H. Wealth and prosperity in pre-palatial Crete: the case of ivory. In KRZYSZKOWSKA, O. H. - NIXON, L. (ed.) Minoan Society. Proceedings of the Cambridge Colloquium 1981. Bristol: Bristol University Press, 1983, p. $163-170$.

PETIT, F. Les tombes circulaires de la Mesara: problèmes d'interprétation des pièces annexes. In LAFFINEUR, R. (ed.) Thanatos. Les Coutumes Funéraires en Égée à l'Âge du Bronze. Liège: Université de l'État à Liège, 1987, p. 35-42 (s. AEGAEUM 1). 


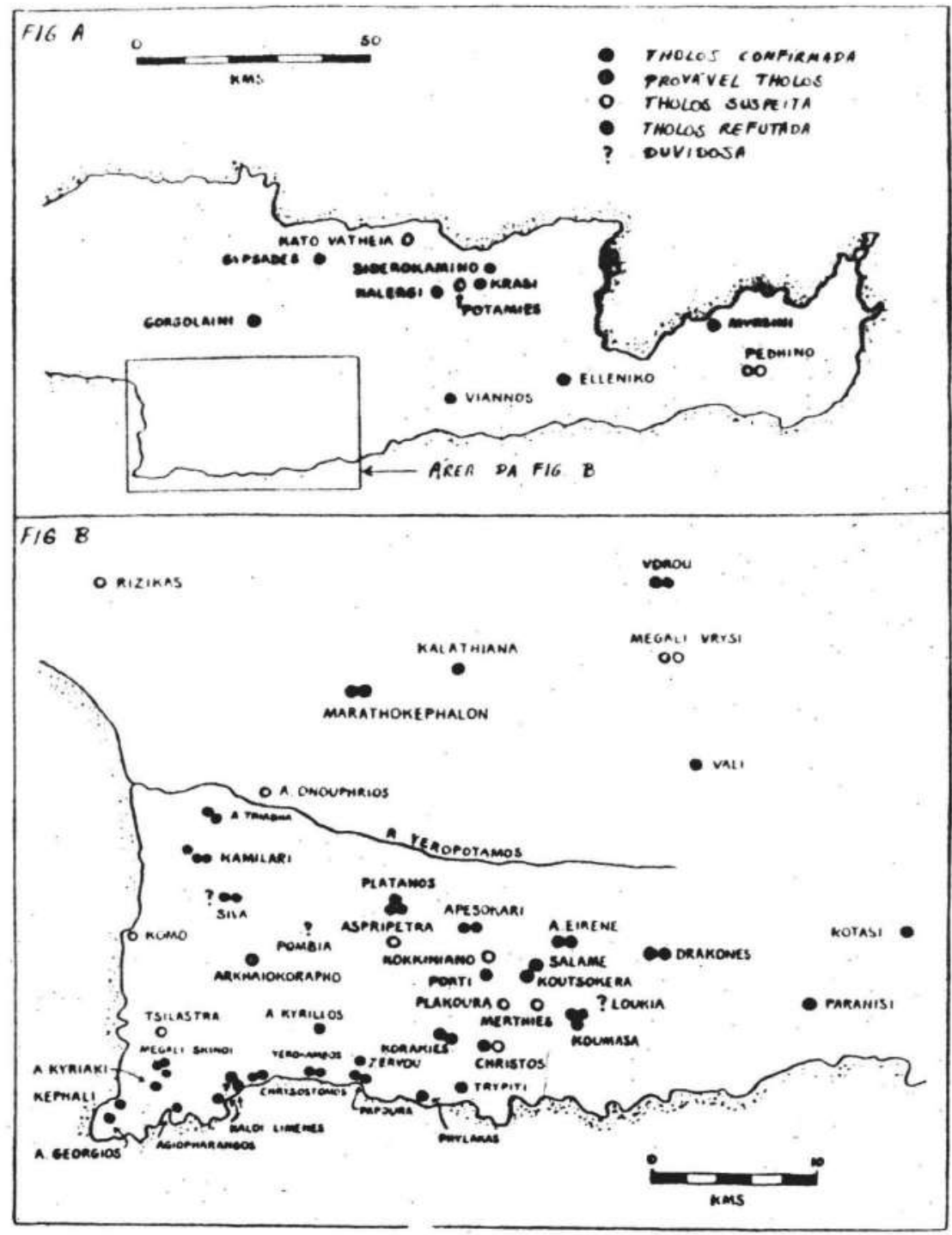

Figura 1.A. Mapa de Creta, com a distribuição de tholoi na ilha

1.B. Mapa da regiẫo de Mesara, com indicação de tholoi do Minóico Antigo e Médio. 